\title{
OÜRICURI
}

\section{SABER SOBRE PÁSSAROS: UM ENTENDIMENTO ETNOORNITOLÓGICO DOS MORADORES DO POVOADO DE CATUNI DA ESTRADA, MUNICÍPIO DE JAGUARARI, NO SERTÃO BAIANO}

\author{
Alan Ferreira BONFIM ${ }^{1}$, Maria Vanderly ANDREA ${ }^{2 *}$, Renato de ALMEIDA ${ }^{3}$, Kaliane Nascimento de \\ OLIVEIRA ${ }^{4}$, Marcel Silva LEMOS $^{5}$, Elon Souza ANICETO ${ }^{6}$
}

${ }^{1}$ Centro de Ciências Agrárias, Ambientais e Biológicas, Universidade Federal do Recôncavo da Bahia, Cruz das Almas, BA, Brasil. E-mail: allan.zootecniaufrb@gmail.com

${ }^{2}$ Centro de Ciências Agrárias, Ambientais e Biológicas, Universidade Federal do Recôncavo da Bahia,

Cruz das Almas, BA, Brasil. *Autora Correspondente. E-mail: mvander@ufrb.edu.br

${ }^{3}$ Centro de Ciências Agrárias, Ambientais e Biológicas, Universidade Federal do Recôncavo da Bahia, Cruz das Almas, BA, Brasil. E-mail: renato.almeida@ufrb.edu.br

${ }^{4}$ Departamento de Produção Animal e Vegetal, Faculdade de Ciências Agrárias, Universidade Federal do Amazonas, Manaus, AM, Brasil. E-mail: kaliane@ufam.edu.br

${ }^{5}$ Centro de Ciências Agrárias, Ambientais e Biológicas, Universidade Federal do Recôncavo da Bahia, Cruz das Almas, BA, Brasil. E-mail: marcel.lemos@ufrb.edu.br

${ }^{6}$ Centro de Ciências e Tecnologias Agropecuárias, Universidade Estadual do Norte Fluminense Darcy Ribeiro, Campos dos Goytacazes, RJ, Brasil. E-mail: elon1995@hotmail.com

Recebido: 17.03.2021 Aceito: 01.06.2021

Resumo: Esta pesquisa foi desenvolvida junto aos moradores da comunidade de Catuni da Estrada, Jaguarari-BA e teve como proposta compreender e inventariar as aves utilizadas como recurso trófico e suas técnicas de captura, zooterápicos, criadas em gaiolas e as lendas/mitos. A pesquisa de campo foi realizada entre os meses de novembro a maio de 2020. Foram entrevistados 50 moradores que utilizam e interagem com a avifauna. A obtenção das informações ocorreu por meio de entrevistas semiestruturadas aplicadas individualmente. A partir das informações obtidas, calculou-se o Valor de Uso (VU) para cada etnoespécies citada. Assim, foram registrados 172 etnoespécies local, para o uso trófico citaram-se 24 etnoespécies, destacando-se Crypturellus parvirostris. As aves citadas são normalmente capturadas através de 13 técnicas, destacando-se o uso da espingarda e "visgo-de-jaca". Registrou-se também algumas espécies não consumidas por questões culturais como Coragypss atratus e Fluvicola nengeta. Para o uso zooterápico registraram-se 11 espécies, com destaque a Columbina talpacoti. Pássaros criados em gaiolas representaram 22 espécies, sendo os principais Paroaria dominicana e Sporophila nigricollis. Nas relações simbólico-ritualísticas, os moradores citaram algumas aves que de acordo com o conhecimento biocultural trazem má sorte e prenuncio de eventos climatológicos. Os resultados apresentados poderão contribuir para informações do conhecimento ecológico local no campo da ornitologia. Numa concepção mais ampla sobre o conhecimento ornitológico "não formal" e formal talvez seja possível auxiliar na implantação de formas mais adequadas de programas de manejo e conservação da avifauna, interligados aos fatores socioeconômicos, culturais, históricos e artísticos, de tal forma a ser conduzido por novos paradigmas socioculturais ecológicos.

Palavras-chave: Avifauna, Conhecimento tradicional, Ornitologia, Preservação, Zootecnia.

Revista Ouricuri, Juazeiro, Bahia, v.11, n.1. p.029-050. jan./jul., 2021. http://www.revistas.uneb.br/index.php/ouricuri | ISSN 2317-0131 


\title{
KNOWLEDGE ABOUT BIRDS: AN ETHNO-ORNITHOLOGICAL UNDERSTANDING BY THE INHABITANTS OF CATUNI DA ESTRADA VILLAGE, COUNTY OF JAGUARARI, IN THE SERTÃO BAIANO
}

\begin{abstract}
This research was developed with the residents of the community of Catuni da Estrada, county of Jaguarari-BA. This study aimed to understand and inventory the birds used as a trophic resource and their capture techniques, zootherapeutic practices, raised in cages, and the legends/myths. The research was carried out between the months of May and November of 2020. Fifty residents who use and interact with birdlife were interviewed. The information was obtained through semi-structured interviews applied individually. From the information obtained, the use-value (VU) was calculated for each ethno-species mentioned. As a result, 172 local ethno-species were recorded, and 24 were mentioned for trophic use, especially Crypturellus parvirostris. The birds are captured using 13 techniques, with emphasis on the use of shotgun and jackfruit sap. There were also some species not eaten for cultural reasons, such as Coragypss atratus and Fluvicola nengeta. The zootherapeutic practices recorded 11 species with the prominence of Columbina talpacoti. For birds raised in cages 22 species were recorded, the main ones were Paroaria dominicana and Sporophila nigricollis. In the symbolic-ritualistic relations, the residents mentioned some birds that, according to their bio-cultural knowledge, bring bad luck and foreshadow climatological events. The results presented may contribute to the information on local ecological knowledge in the ornithology field, allowing that a broader conception of non-formal and formal ornithological knowledge can assist in the implementation of more appropriate forms of programs for the management and conservation of birdlife, linked to socioeconomic, cultural, historical, and artistic factors in such a way that new ecological socio-cultural paradigms may be conducted.
\end{abstract}

Keywords: Birdlife, Traditional knowledge, Ornithology, Preservation, Animal husbandry.

\section{CONOCIENDO A LAS AVES: UN ENTENDIMIENTO ETNOORNITOLÓGICO DE LOS RESIDENTES DEL PUEBLO CATUNI DA ESTRADA, MUNICIPIO DE JAGUARARI, EN EL SERTÃO BAIANO}

Resumen: Esta investigación se desarrolló con los habitantes de la comunidad de Catuni da Estrada, Jaguarari-BA y tuvo como propuesta, hacer el inventario de las aves utilizadas como recurso trófico y su técnica de captura, el uso en la zooterapia, la crianza en cautiverio y las leyendas / mitos em torno a estas aves. La investigación de campo se llevó a cabo entre los meses de noviembre y mayo de 2020. Se entrevistaron a 50 residentes que utilizan e interactúan con la avifauna. La información se obtuvo mediante entrevistas semiestructuradas aplicadas individualmente. A partir de la información obtenida, se calculó el Valor en Uso (VU) para cada etnoespecie mencionada. Así, se registraron 172 etnoespecies locales, para uso trófico se citaron 24 etnoespecies, destacando Crypturellus parvirostris. Las aves mencionadas normalmente son capturadas mediante 13 técnicas, principalmente con el uso de la escopeta y el "muérdago de jaca". También se registraron algunas especies no consumidas por motivos culturales, como Coragypss atratus y Fluvicola nengeta. Para uso zooterápico se registraron 11 especies, con énfasis en Columbina talpacoti. Las aves criadas en jaulas representaron 22 especies, siendo las principales Paroaria dominicana y Sporophila nigricollis. En las relaciones simbólicoritualísticas, los pobladores mencionaron algunas aves que según el conocimiento biocultural, traen mala suerte y presagian eventos climatológicos. Los resultados presentados pueden contribuir a la información sobre el conocimiento ecológico local en el campo de la ornitología. En una concepción más amplia del conocimiento ornitológico "no formal" y formal, puede ser posible ayudar en la implementación de programas más apropiados de manejo y conservación de la avifauna, vinculados a factores socioeconómicos, culturales, históricos y artísticos, de tal manera que sea conducida por nuevos paradigmas socioculturales ecológicos.

Palabras clave: avifauna, conocimientos tradicionales, ornitología, preservación, cría de animales.

Revista Ouricuri, Juazeiro, Bahia, v.11, n.1. p.029-050. jan./jul., 2021. http://www.revistas.uneb.br/index.php/ouricuri | ISSN 2317-0131 


\section{INTRODUÇÃO}

O conjunto das complexas maneiras de interação entre humanos e fauna pode ser traçado por meio de diferentes recortes científicos, a depender da linha teórica que será abordada (Begossi, 1993). Historicamente, supõe-se que a ciência etnozoológica é a área responsável pelo entendimento das inter-relações que os variados povos mantêm com os animais, tendo originado simultaneamente ao surgimento da espécie humana (Alves e Souto, 2010).

A etnozoologia faz parte de um campo de estudo abrangente - Etnobiologia. Surgida do campo da sociolinguística e da antropologia cognitiva, a etnobiologia é um campo de pesquisa transdisciplinar que busca entender as diversas percepções culturais da relação do homem com a natureza, assim como a maneira e propósito de como estas percepções são alinhadas e classificadas pelas sociedades através da linguagem (Posey, 1987; Begossi, 1993).

Neste sentido, dentre as diferentes áreas etnozoológicas cabe aqui a etnoornitologia, uma variante que busca analisar a performance existente entre seres humanos e aves silvestres. De acordo com Farias e Alves (2007), a etnoornitologia busca entender as relações cognitivas, comportamentais e simbólicas existentes entre a espécie humana e as aves, cruzando-se o conhecimento a partir da compreensão destas relações sob diversos contextos culturais e ecológicos.

Portanto, investiga fenômenos que vão além da simples interface entre a ciências biológicas e antropologia; uma vez que as aves são tidas como símbolos arquetípicos presentes no imaginário de várias culturas ao longo da história humana sobre a terra (Silveira, 2010). Logo, estudar a relação da comunidade de Catuni da Estrada com avifauna local se torna fator crucial para entender a cultura, assim como o estado em que se encontra as aves silvestres. Além disso, há ainda uma persistência das atividades de caça na comunidade em questão, que, certamente está interligada ao contexto cultural e socioeconômico, sendo uma atividade transmitida de geração para geração.

Quando a fauna se torna importante para uma determinada comunidade ela passa a fazer parte de seu contexto e de seus pensamentos, estabelecendo-se então diversas relações dos seres humanos com os animais, sejam elas utilitárias (alimentação, vestuário, medicinal, mágico-religioso, etc.), simbólicas (lendas, mitos), ou sua comercialização ilegal (Mason, 1899; Bennett et al.,1999; Alves et al., 2009; Corona, 2011).

Em pesquisas realizadas no Semiárido Brasileiro, Alves et al (2010) apontam o uso de aves silvestres, que apesar de ser uma prática ilegal, é bem comum, e em conjunto com outras ameaças, tem contribuído para o declínio da avifauna local. 
Nesse aspecto, é de extrema importância que o conhecimento ecológico tradicional sobre aves silvestres seja registrado. Objetivou-se investigar a relação dos moradores do povoado de Catuni da Estrada com avifauna local, identificando como são percebidas, caracterizadas e utilizadas.

\section{MÉTODOS}

O trabalho foi desenvolvido no povoado de Catuni da Estrada (10²0'39.9"S 40¹1'01.4"W), município de Jaguarari, localizado na Mesorregião do centro norte Baiano, e micro região de Senhor do Bonfim, no Território de Identidade do Piemonte Norte do Itapicuru e distante $398 \mathrm{~km}$ da Capital Salvador, entre os meses de novembro a maio de 2020.

A pesquisa de campo ocorreu após a aprovação pelo Comitê em Pesquisa da Universidade Federal do Recôncavo da Bahia - CEP/UFRB (CAAE: 26262019.1.0000.0056/2019) (Anexo 1). Foram realizadas entrevistas com 50 moradores locais, que conhecem e fazem uso de aves silvestres com diferentes finalidades. A escolha dos moradores se deu a partir da técnica Bola-de-Neve (Biernacki e Waldorf, 1981), que consiste em localizar os demais entrevistados alvos da pesquisa a partir da indicação dos primeiros.

Os dados foram obtidos através de entrevistas, utilizando questionários semiestruturados, com perguntas abertas referentes ao uso dos animais pela população local, integrado a entrevistas livres feitas de modo individual e conversas informais no dia a dia (Mello, 1995; Huntington, 2000; Albuquerque e Lucena, 2004). Os participantes foram convidados a assinar um Termo de Consentimento Livre e Esclarecido - TCLE, no qual constavam informações referentes ao objetivo da pesquisa, e as formas de utilização dos dados coletados.

Quando necessário, foi utilizado guia de campo (Sigrist, 2015) para auxiliar na identificação das espécies com nome científico de acordo com a Lista das Aves do Brasil (CBRO, 2015). Assim, para determinar a importância cinegética relativa das espécies calculou-se seu respectivo Valor de Uso (VU), (método adaptado por Phillips, et al., 1994), que possibilita demonstrar a importância relativa da espécie conhecida e utilizada localmente.

O Valor de Uso foi calculado através da fórmula:

$\mathrm{VU}=\frac{\boldsymbol{\Sigma} \mathrm{U}}{\boldsymbol{n}}$

Onde,

VU = Valor de Uso da Espécie;

$\mathbf{U}=$ número de citações por espécie;

$\mathbf{n}=$ número de informantes.

Os dados foram processados no programa Excel 2013 para posterior elaboração da lista de aves de Catuni da Estrada. 


\section{RESULTADOS}

No povoado de Catuni da Estrada as aves são utilizadas de diferentes maneiras: alimento (interação trófica), remédio em atividades de medicina popular (interação zooterápicas), criação em gaiolas (interação sócio afetiva) e para o comércio (interação econômica). Neste sentido, os indivíduos entrevistados citaram 172 nomes de aves entre silvestres $(n=170)$ e domésticas $(n=02)$. Ressalta-se que 119 espécies possuem sinonímias, ou seja, são um ou mais nomes além do comumente conhecido e utilizados pelos moradores para designar uma mesma etnoespécies (Tabela 1).

Tabela 1: Lista das etnospecies $(n=172)$ mencionadas pelos habitantes do povoado de Catuni da Estrada, município de Jaguarari, Bahia, Brasil, 2020.

\begin{tabular}{|c|c|c|}
\hline Etnospecies & Sinonímia & Nome Científico \\
\hline Alma-de-gato & Tincoã & Piaya cayana (Linnaeus, 1766) \\
\hline Andorinha & - & $\begin{array}{l}\text { Pygochelidon cyanoleuca cyanoleuca (Vieillot, } \\
\text { 1817) }\end{array}$ \\
\hline Anum-branco & - & Guira guira (Gmelin, 1788) \\
\hline Anum-preto & - & Crotophaga ani (Linnaeus, 1758) \\
\hline Aracuã-de-barringa-branca & Aracuã & Ortalis araucuan (Spix, 1825) \\
\hline Arapaçu-do-cerrado & - & Lepidocolaptes angustirostris (Vieillot, 1818). \\
\hline Araponga & - & Procnias nudicollis (Vieillot, 1817) \\
\hline Ariramba-de-cauda-ruiva & Bico-de-sovela/bizungão & Galbula ruficauda (Cuvier, 1816) \\
\hline Asa-branca & Pombo-do-mato/pombão & Patagioenas picazuro (Temminck, 1813) \\
\hline Asanhaçu-cinzento & Sanhaçu-cinzento & Tangara sayaca (Linnaeus, 1766) \\
\hline Asanhaçu-de-coqueiro & Sanhaçu-de-coqueiro & Tangara palmarum (Wied, 1821) \\
\hline Azulão & - & Cyanoloxia brissonii (Lichtenstein, 1823) \\
\hline Azulão-de-chiqueiro & Chupim/vira-bosta/maria-preta & Molothrus bonariensis (Gmelin, 1789) \\
\hline Bacurau & - & Nyctidromus albicollis (Gmelin, 1789) \\
\hline Bacurau-tesoura & Coruja-rabo-de-tesoura & Hydropsalis torquata (Gmelin, 1789) \\
\hline Bacurauzinho & - & Nannochordeiles pusillus (Gould, 1861) \\
\hline $\begin{array}{l}\text { Beija-flor-asa-de-sabre- } \\
\text { cinza }\end{array}$ & Asa-de-sabre & Campylopterus largipennis (Boddaert, 1783) \\
\hline $\begin{array}{l}\text { Beija-flor-balança-rabo- } \\
\text { canela }\end{array}$ & Beija-flor-rajado & Glaucis dohrnii (Bourcier \& Mulsant, 1852) \\
\hline Beija-flor-bandeira & Bandeirinha & Discosura longicaudus (Gmelin, 1788) \\
\hline Beija-flor-cinza & - & Aphantochroa cirrochloris (Vieillot, 1818) \\
\hline $\begin{array}{l}\text { Beija-flor-de-garganta- } \\
\text { verde }\end{array}$ & Beija-flor-verde & Amazilia fimbriata (Gmelin, 1788) \\
\hline Beija-flor-de-rabo-branco & Rabo-branco-acanelado & Phaethornis pretrei (Lesson \& Delattre, 1839) \\
\hline Beija-flor-do-peito-azul & Beija-flor-azulzinho/bizunga & Amazilia lactea (Lesson, 1832) \\
\hline Beija-flor-mirim/pequeno & Besourinho-do-bico-vermelho & Chlorostilbon lucidus (Shaw, 1812) \\
\hline Beija-flor-tesoura & Beija-flor-rabo-de-tesoura & Eupetomena macroura (Gmelin, 1788) \\
\hline Beija-flor-vermelho & Papo-de-fogo & Chrysolampis mosquitus (Linnaeus, 1758) \\
\hline Bem-ti-vi & - & Pitangus sulphuratus (Linnaeus, 1766) \\
\hline Bico-assovelado & - & Ramphocaenus melanurus (Vieillot, 1819) \\
\hline
\end{tabular}

Revista Ouricuri, Juazeiro, Bahia, v.11, n.1. p.029-050. jan./jul., 2021. http://www.revistas.uneb.br/index.php/ouricuri | ISSN 2317-0131 


\begin{tabular}{|c|c|c|}
\hline Bico-de-lacre & Bico-de-lata & Estrilda astrild (Linnaeus, 1758) \\
\hline Bico-de-pimenta & Bico-de-ouro & Saltatricula atricollis (Vieillot, 1817) \\
\hline Bico-de-veludo & - & Schistochlamys ruficapillus (Vieillot, 1817) \\
\hline Bigodinho & Bigode & Sporophila lineola (Linnaeus, 1758) \\
\hline Cablocinho & - & Sporophila bouvreuil (Statius Muller, 1776) \\
\hline Caboré & Caburé & Glaucidium brasilianum (Gmelin, 1788)) \\
\hline Cambacica & $\begin{array}{l}\text { Chupa-licuri/chupa-lima/chupincó/caga- } \\
\text { sebo/sibiti }\end{array}$ & Coereba flaveola (Linnaeus, 1758) \\
\hline $\begin{array}{l}\text { Canário-da-terra- } \\
\text { verdadeiro }\end{array}$ & Cánario-de-briga & Sicalis flaveola (Linnaeus, 1766) \\
\hline Canário-de-lote & Tipio & Sicalis Iuteola (Sparrman, 1789) \\
\hline Cancão & Gralha-cancã & Cyanocorax cyanopogon (Wied, 1821) \\
\hline Carcará & Caracará & Caracara plancus (Miller, 1777) \\
\hline Cardeal & Cardeal-do-nordeste & Paroaria dominicana (Linnaeus, 1758) \\
\hline Casaca-de-couro & Cabeleira/maria-cabeleira & Pseudoseisura cristata (Spix, 1824) \\
\hline Cauã & Acauã & Herpetotheres cachinnans (Linnaeus, 1758) \\
\hline Cava-chão & Rapazinho-dos-velhos & Nystalus maculatus (Gmelin, 1788) \\
\hline $\begin{array}{l}\text { Choca-barrada-do- } \\
\text { nordeste }\end{array}$ & Corró & Thamnophilus capistratus (Lesson, 1840) \\
\hline Choca-do-nordeste & - & Sakesphorus cristatus (Wied, 1831) \\
\hline Chorão & - & Sporophila leucoptera (Vieillot, 1817) \\
\hline Choró-boi & - & Taraba major (Vieillot, 1816) \\
\hline $\begin{array}{l}\text { Chorozinho-de-asa- } \\
\text { vermelha }\end{array}$ & - & $\begin{array}{l}\text { Herpsilochmus rufimarginatus (Temminck, } \\
\text { 1822) }\end{array}$ \\
\hline Codorna-amarela & Codorna-comum/codorna-pimpão & Nothura maculosa (Temminck, 1815) \\
\hline Codorna-do-nordeste & Codorniz/curduniz & Nothura boraquira (Spix, 1825) \\
\hline Coleirinha & Coleira/cólera & Sporophila caerulescens (Vieillot, 1823) \\
\hline Coleiro-do-brejo & Colera-do-brejo & Sporophila collaris (Boddaert, 1783) \\
\hline Coruja-buraqueira & Coruja & Athene cunicularia (Molina, 1782) \\
\hline Coruja-de-orelha & Coruja-orelhuda & Asio clamator (Vieillot, 1808) \\
\hline Corujão & Jacurutu & Bubo virginianus (Gmelin, 1788) \\
\hline Corujinha-do-mato & Corujinha & Megascops choliba (Vieillot, 1817) \\
\hline Curió & - & Sporophila angolensis (Linnaeus, 1766) \\
\hline Farinha-aí & Tem-farinha-aí & Myrmorchilus strigilatus (Wied, 1831) \\
\hline Feijão-verde & Bico-de-veludo & Schistochlamys ruficapillus (Vieillot, 1817) \\
\hline Frango-d-água-comum & Galinha-d'água/jaçanã-galo & Gallinula galeata (Lichtenstein, 1818) \\
\hline Galinha & Galinha-doméstica & Gallus gallus domesticus (Linnnaeus, 1758) \\
\hline Galo de campina & Tico-tico-rei-cinza/abre-e-fecha/maria-fita & Coryphospingus pileatus (Wied, 1821) \\
\hline Garça & Gauça & Bulbucus ibis (Linnaus, 1758) \\
\hline Garrincha & Corruíra & Troglodytes musculus (Naumann, 1823) \\
\hline $\begin{array}{l}\text { Garrincha-de-barriga- } \\
\text { vermelha }\end{array}$ & - & Cantorchilus leucotis (Lafresnaye, 1845) \\
\hline Garrinchão-do-bico-grande & Rouxinol & Cantorchilus longirostris (Vieillot, 1819) \\
\hline Garrincha-pai-avô & - & Pheugopedius genibarbis (Swainson, 1838) \\
\hline Gaturamo-verdadeiro & Curiatá/cíntia & Euphonia violacea (Linnaeus, 1758) \\
\hline Gavião-caboclo & Gavião-marrom & Heterospizias meridionalis (Latham, 1790) \\
\hline Gavião-caracoleiro & - & Chondrohierax uncinatus (Temminck, 1822) \\
\hline
\end{tabular}

Revista Ouricuri, Juazeiro, Bahia, v.11, n.1. p.029-050. jan./jul., 2021. http://www.revistas.uneb.br/index.php/ouricuri | ISSN 2317-0131 


\begin{tabular}{|c|c|c|}
\hline Gavião-carijó & Pega-pinto & Rupornis magnirostris (Gmelin, 1788) \\
\hline Gavião-carrapateiro & Carrapateiro & Milvago chimachima (Vieillot, 1816) \\
\hline Gavião-cauré & - & Falco rufigularis (Daudin, 1800) \\
\hline Gavião-chimango & - & Milvago chimango (Vieillot, 1816) \\
\hline Gavião-da-serra & Águia-serrana/águia-chilena & Geranoaetus melanoleucus (Vieillot, 1819) \\
\hline Gavião-de-cabeça-cinza & - & Leptodon cayanensis (Latham, 1790) \\
\hline Gavião-de-cauda-curta & - & Buteo brachyurus (Vieillot, 1816) \\
\hline Gavião-do-pescoço-branco & - & Pseudastur polionotus(Kaup, 1847) \\
\hline Gavião-miudinho & Gavião-miúdo/gavião-piquinininho & Accipiter striatus (Kaup, 1850) \\
\hline Gavião-papa-gafanhoto & - & Buteo swainsoni (Bonaparte, 1838) \\
\hline Gavião-pedrez & Gavião-cinza & Buteo nitidus (Latham, 1790) \\
\hline Gavião-peneira & Peneira & Elanus leucurus (Vieillot, 1818) \\
\hline Gavião-peregrino & Falcão-peregrino & Falco peregrinus (Tunstall, 1771) \\
\hline Gavião-real & Gavião-verdadeiro & Harpia harpyja (Linnaeus, 1758) \\
\hline Gavião-ripina & Ripina & Harpagus bidentatus (Latham, 1790) \\
\hline Gaviãozinho-da-serra & Gavião-pernilongo/gavião-cinza-azulado & Geranospiza caerulescens (Vieillot, 1817) \\
\hline Golinho & - & Sporophila albogularis (Spix, 1825) \\
\hline Graveteiro & Patativa & Phacellodomus ruber (Vieillot, 1817) \\
\hline Jacu & Jacucaca & Penelope jacucaca (Spix, 1825) \\
\hline Jesus-meu-deus & Tico-tico & Zonotrichia capensis (Statius Muller, 1776) \\
\hline João-corta-pau & - & Antrostomus rufus (Boddaert, 1783) \\
\hline João-de-barro & Janica-de-barro & Furnarius rufus (Gmelin, 1788) \\
\hline Juriti & Juriti-pupu & Leptotila verreauxi (Bonaparte, 1855) \\
\hline Juriti-vermelha & Juriti-roxa & Geotrygon violacea (Temminck, 1809) \\
\hline Lagarteiro & Papa-lagarta-acanelado & Coccyzus melacoryphus (Vieillot, 1817) \\
\hline Lavandeira & Lavadeira & Fluvicola nengeta (Linnaeus, 1766) \\
\hline Lavandeira-de-cara-branca & Lavadeira-de-cara-branca & Fluvicola albiventer (Spix, 1825) \\
\hline Maracanã-pequena & - & Diopsittaca nobilis (Linnaeus, 1758) \\
\hline Maria-tola & Guaracava-de-barriga-amarela & Elaenia flavogaster (Thunberg, 1822) \\
\hline Martim-pescador-grande & - & Megaceryle torquata (Linnaeus, 1766) \\
\hline Martim-pescador-pequeno & Martim-pescador/ariramba & Chloroceryle americana (Gmelin, 1788) \\
\hline Martim-pescador-verde & - & $\begin{array}{l}\text { Chloroceryle amazona (Clements checklist, } \\
\text { 2014) }\end{array}$ \\
\hline Mergulhão & - & Megaceryle torquata (Linnaeus, 1766) \\
\hline Mocho-dos-banhado & - & Asio flammeus (Pontoppidan, 1763) \\
\hline Nambu & Lambu-pé-vermelho & Crypturellus parvirostris (Wagler, 1827) \\
\hline Nambu-chororó & Lambu-pé-roxo & Crypturellus tataupa (Termminck, 1815) \\
\hline Noivinha & Viuvinha & Xolmis irupero (Vieillot, 1823) \\
\hline Papa-capim & Coleiro-baiano/baianinho/pacapim & Sporophila nigricollis (Vieillot, 1823) \\
\hline Paquinha & Polícia-inglesa-do-sul/papo-d-fogo & Sturnella superciliaris (Bonaparte, 1850) \\
\hline Pardal & - & Passer domesticus (Linnaeus, 1758) \\
\hline Passarinho-de-arroz & Pássaro-de-arroz & Chrysomus ruficapillus (Vieillot, 1819) \\
\hline Pássaro-preto & Passo-preto/assum-preto/graúna & Gnorimopsar chopi(Vieillot, 1819) \\
\hline Pato & Pato-do-mato & Cairina moschata (Linnaeus, 1758) \\
\hline
\end{tabular}

Revista Ouricuri, Juazeiro, Bahia, v.11, n.1. p.029-050. jan./jul., 2021. http://www.revistas.uneb.br/index.php/ouricuri | ISSN 2317-0131 


\begin{tabular}{|c|c|c|}
\hline Pato-marreco & Pato-real & $\begin{array}{l}\text { Dendrocygna autumnalis, Amazonetta } \\
\text { brasiliensis }\end{array}$ \\
\hline Pavãozinho-do-mato & & Dromococcyx pavoninus \\
\hline Pêga & Pêga-da-meia-noite-preta/peguinha & Icterus cayanensis (Linnaeus, 1766) \\
\hline Perdiz & - & Rhynchotus rufescens (Temminck, 1815) \\
\hline Periquitinho-de-são-josé & Tuim/guizo/guirra & Forpus xanthopterygius (Spix, 1824) \\
\hline Periquito-da-Caatinga & Priquitinho & Eupsittula cactorum (Kuhl, 1820) \\
\hline $\begin{array}{l}\text { Pica-pau-anão-de-pintas- } \\
\text { amarelas }\end{array}$ & - & Picumnus exilis (Lichtenstein, 1823) \\
\hline Pica-pau-branco & - & Melanerpes candidus (Otto, 1796) \\
\hline Pica-pau-chorão & - & Veniliornis mixtus (Boddaert, 1783) \\
\hline $\begin{array}{l}\text { Pica-pau-de-cabeça- } \\
\text { amarela }\end{array}$ & Pica-pau-louro/topete-louro & Celeus flavescens (Gmelin, 1788) \\
\hline $\begin{array}{l}\text { Pica-pau-de-cabeça- } \\
\text { vermelha }\end{array}$ & Pica-pau-de-topete-vermelho/pinica-pau & Campephilus melanoleucos (Gmelin, 1788) \\
\hline Pica-pau-dourado-escuro & - & Piculus chrysochloros (Vieillot, 1818) \\
\hline Pica-pau-pedrez & Orácio/pica-pau-verde-barrado/carijó & Colaptes melanochloros (Gmelin, 1788) \\
\hline Picapauzinho-avermelhado & - & Veniliornis affinis (Swainson, 1821) \\
\hline Picapauzinho-do-nordeste & Picapauzinho-anão & Veniliornis passerinus (Linnaeus, 1766) \\
\hline Pintado & Pica-pau-chorão & Veniliornis mixtus (Boddaert, 1783) \\
\hline Piriquitinho-rico & Periquito-rico & Brotogeris tirica (Gmelin, 1788) \\
\hline Pitiguari & Bico-de-osso & Cyclarhis gujanensis (Gmelin, 1789) \\
\hline Pomba-de-seca & $\begin{array}{l}\text { Pomba-verdadeira/ribançã/pomba-do- } \\
\text { sertão/pomba-de-bando }\end{array}$ & Zenaida auriculata (Des Murs, 1847) \\
\hline Quem-quem & Quero-quero & Vanellus chilensis (Molina, 1782) \\
\hline Rabão-de-tesoura & Tesourinha & Tyrannus savana (Daudin, 1802) \\
\hline Rasga-mortalha & Coruja & Tyto furcata (Temminck, 1827) \\
\hline Rolinha-azul & Rola-azul & Claravis pretiosa (Ferrari-Perez, 1886) \\
\hline Rolinha-branca & Rolinha-cinza & Columbina picui (Temminck, 1813) \\
\hline Rolinha-caldo-de-feijão & Rolinha-vermelha/rolinha-roxa/paquinha & Columbina talpacoti (Temminck, 1810) \\
\hline Rolinha-de-asa-canelada & - & Columbina minuta (Linnaeus, 1766) \\
\hline Rolinha-fogo-pagou & Rolinha-de-asa-canela/fogo-apagou & Columbina squammata (Lesson, 1831) \\
\hline Sabiá-barranqueira & Sabiá-barranco & Turdus leucomelas (Vieillot, 1818) \\
\hline Sabiá-bico-de-osso & Sabiá-branca/poca & Turdus amaurochalinus (Cabanis, 1850) \\
\hline Sabiá-coca & Sabiá-laranjeira/coca & Turdus rufiventris (Vieillot, 1818) \\
\hline Sabiá-da-mata & - & Turdus fumigatus (Lichtenstein, 1823) \\
\hline Sabiá-de-sebo & Sabiá-do-campo & Mimus saturninus (Lichtenstein, 1823) \\
\hline Sabiá-gongá & - & Saltator coerulescens (Vieillot, 1817) \\
\hline Saíra-amarela & Assanhaçinho-de-pimenta-de-galinha & Tangara cayana (Linnaeus, 1766) \\
\hline Saíra-azul & Saí-azul & Dacnis cayana (Linnaeus, 1766) \\
\hline Saíra-sete-cor & Saíra-sete-cor & Tangara seledon (Statius Muller, 1776) \\
\hline Saitica & Saci & Tapera naevia (Linnaeus, 1766) \\
\hline Sangue-de-boi & Tiê-sangue & Ramphocelus bresilius (Linnaeus, 1766) \\
\hline Sanhaçu-cinzento & - & Tangara sayaca (Linnaeus, 1766) \\
\hline Sanhaçu-de-coqueiro & Sanhaçu-verde & Tangara palmarum (Wied, 1821) \\
\hline Saracura & Três-pote & Aramides cajaneus (Statius Muller, 1776) \\
\hline Sariema & Siriema/seriema & Cariama cristata (Linnaeus, 1766) \\
\hline
\end{tabular}

Revista Ouricuri, Juazeiro, Bahia, v.11, n.1. p.029-050. jan./jul., 2021. http://www.revistas.uneb.br/index.php/ouricuri | ISSN 2317-0131 


\begin{tabular}{lll} 
Sibinho & Balança-rabo-de-chapéu-preto & Polioptila plumbea (Gmelin, 1788) \\
Siriri & Suiriri & Tyrannus melancholicus (Vieillot, 1819) \\
Siriri-cavaleiro & Bem-ti-vi-carrapateiro & Machetornis rixosa (Vieillot, 1819) \\
Socó & Socó-boi & Tigrisoma lineatum (Boddaert, 1783) \\
Sofrês & Sofrê/corrupião & Icterus jamacaii (Gmelin, 1788) \\
Tempera-viola & Pimenteira & Saltator maximus (Statius Muller, 1776) \\
Tiziu & Maria-pretinha & Volatinia jacarina ((Linnaeus, 1766)) \\
Trinca-ferro & Estevo/estevão & Saltator similis (d'Orbigny \& Lafresnaye, 1837) \\
Urubu-de-cabeça-amarela & - & Cathartes burrovianus (Cassin, 1845) \\
Urubu-de-cabeça-preta & - & Coragypss atratus (Bechstein, 1793) \\
Urubu-de-cabeça-vermelhat & Urubu-merdeiro & Cathartes aura (Linnaeus, 1758) \\
Urubu-rei & - & Sarcoramphus papa (Linnaeus, 1758) \\
Vim-vim & Fim-fim & Euphonia chlorotica (Linnaeus, 1766) \\
Vim-vim-grande & - & Euphonia xanthogaster \\
Vô-da-lua & Mãe-da-lua & xanthogaster (Sundevall, 1834) \\
Xeque & - & Nyctibius griseus (Gmelin, 1789) \\
Zabelê & - & Agelaioides fringilarius (Spix, 1824) \\
\hline
\end{tabular}

Das etnoespécies citadas, nove não puderam ser identificadas porque os entrevistados não souberam prestar maiores informações sobre a morfologia e comportamento delas; nem mesmo o auxílio do guia de aves permitiu determinar qual era a ave citada considerando apenas a informação sobre o nome popular. Entre as 9 espécies citadas podem ser destacadas: "Gavião-azul", "Couro-deboi", "Para-bala", "Tuntum" e "Zé-pintinho". Talvez seja necessário aprofundar o estudo para identificação destas criaturas insólitas.

Dentre as etnoespécies, as mais citadas pelos entrevistados foram Cardeal-do-nordeste Paroaria dominicana (50,0\%); Sabiá-coca - Turdus rufiventris (48,0\%); Galo-de-campina Coryphospingus pileatus (46,0\%); Sofrê - Icterus jamacaii (40,0\%); Coleira - Sporophila caerulescens (38,0\%); Beija-flor-azulzinho - Eupetomena macroura (36,0\%) e Perequitinho-de-São-José - Forpus xanthopterygius (32,0\%) (Fig 1).

Fig 1: Etnoespécies mais citadas no âmbito social de Catuni da Estrada, Bahia, Brasil. (A) Beija-florazulzinho; (B) Cardeal; (C) Coleirinha; (D) Sofrê. (BONFIM, 2020). 


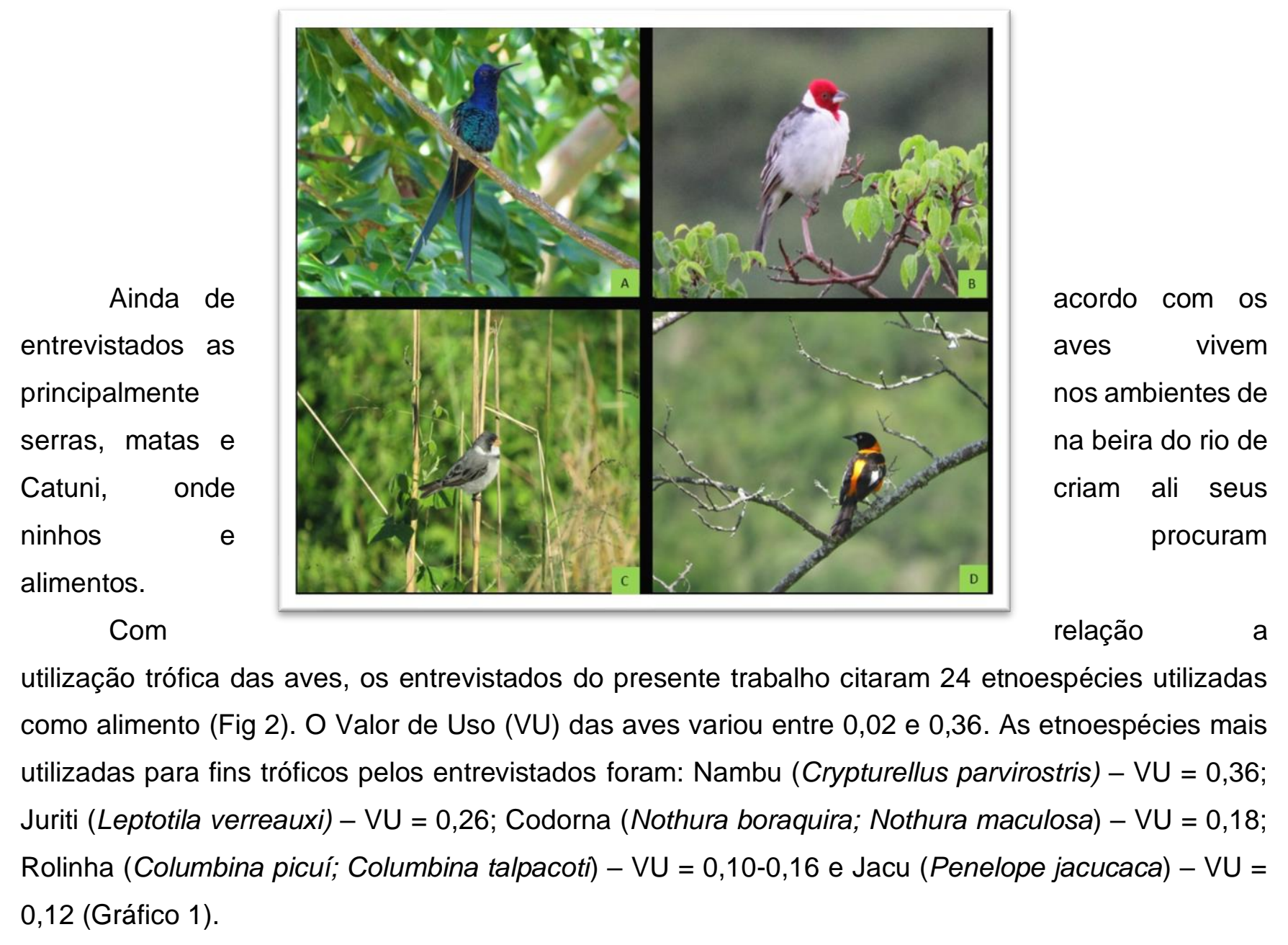

Gráfico 1. Etnoespécies utilizadas para consumo em Catuni da Estrada com seus respectivos Valor de Uso. 


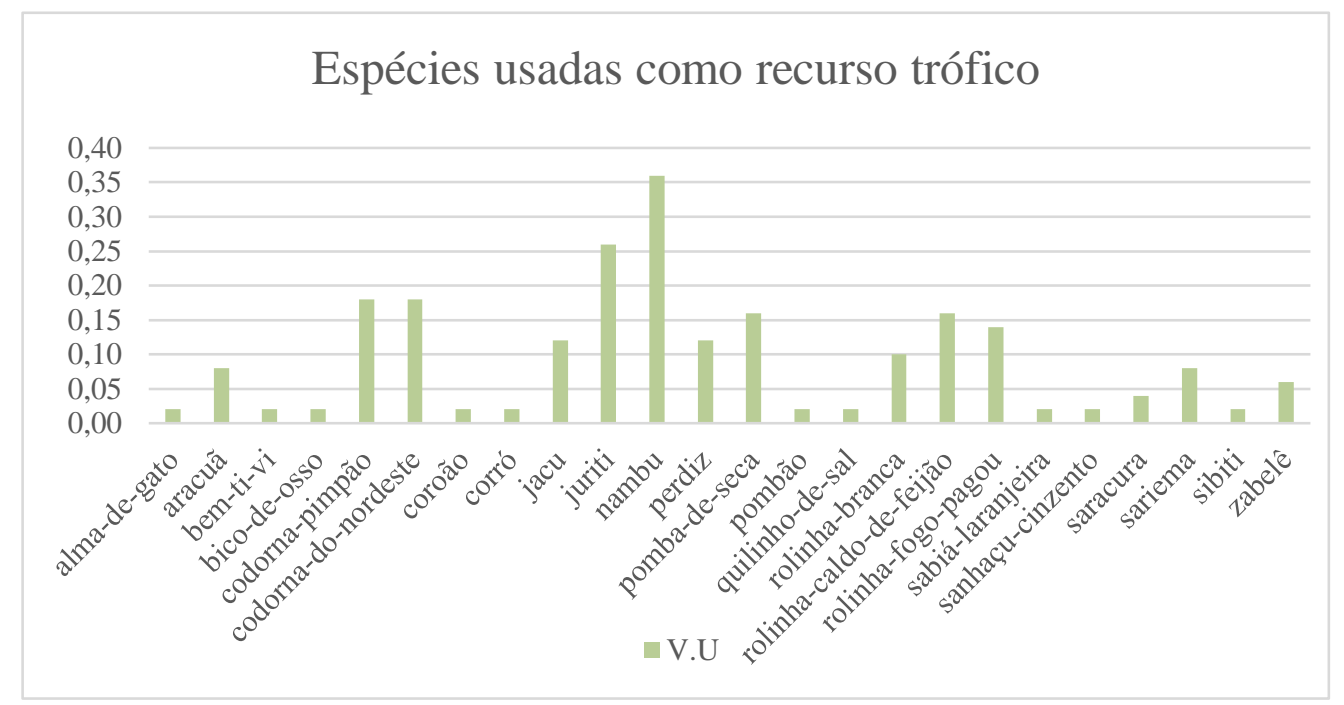

Dentre as aves citadas foram registradas etnoespécies que estão na lista de aves do Livro Vermelho de Fauna Brasileira Ameaçada de Extinção: volume 1 (Brasil, 2018), marcadas como espécies críticas. São elas, Jacu (Penelope jacucaca) da família CRACIDAE e Zabelê (Crypturellus noctivagus) da família TINAMIDAE, ambas na categoria de vulnerabilidade.

Em Catuni da Estrada foram citadas 13 (treze) maneiras de caça, consistindo em técnicas (armadilhas, instrumentos) utilizadas na captura das aves da região no entorno da comunidade.

Ainda de acordo com alguns entrevistados, existem restrições tabus alimentares a certas aves. Foram citados o Urubu-de-cabeça-preta (Coragypss atratus) com $\mathrm{n}=11$ e a Lavandeira (Fluvicola nengeta) $\mathrm{n}=6$ (Gráfico 2). Também foram mencionados o Pardal (Passer domesticus) e o Xeque (Agelaioides fringilarius) por viverem em ambientes humanos, além da Garça (Bulbucus íbis) que se alimenta de carrapatos. Existem, ainda, aquelas aves que permanecem tabus por fatores religiosas e espiritualistas, tendo como exemplo: Jesus-Meu-Deus (Zonotrichia capensis), Coruja rasga-mortalha (Tyto furcata).

Fig 2: Aves usadas para alimentação na comunidade de Catuni da Estrada, Bahia, Brasil. Visto que a espécie Penelope Jacucaca está na lista de aves ameaçadas. (A) Alma-de-gato; (B) Rolinha-branca; (C) Três-pote; (D) Jacu (BONFIM, 2020). 


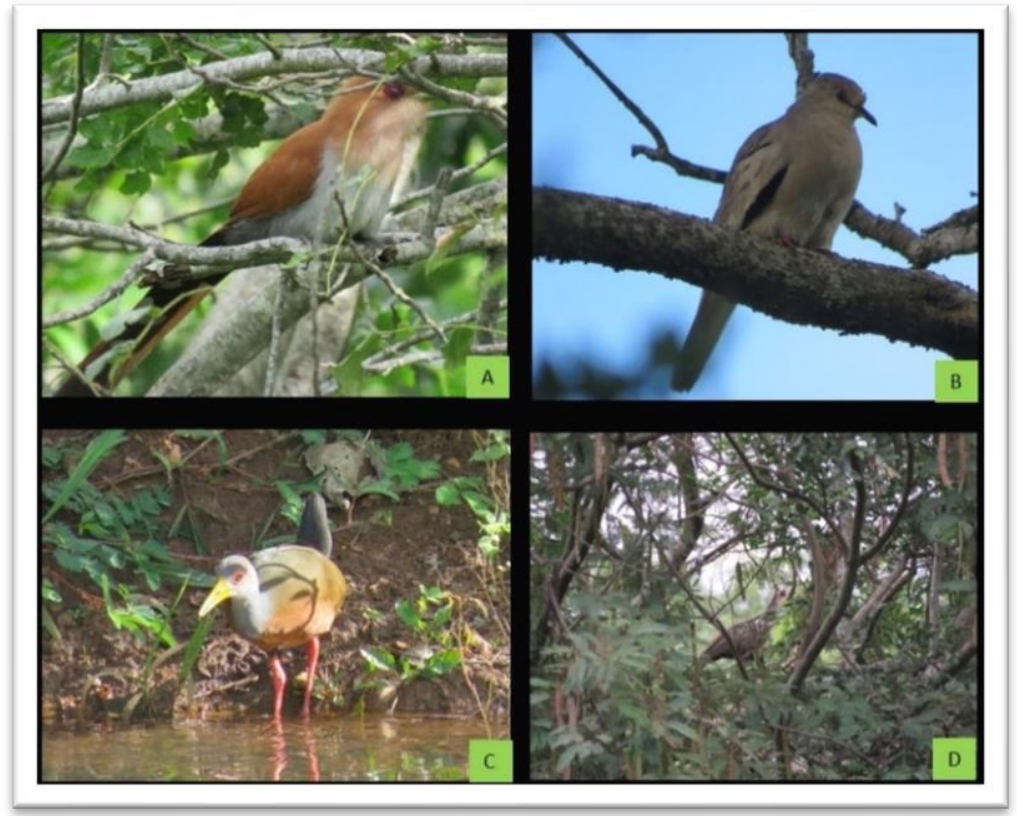

Gráfico 2: Aves não consumidas pelos moradores do povoado de Catuni da Estrada, com seus respectivos números de citação

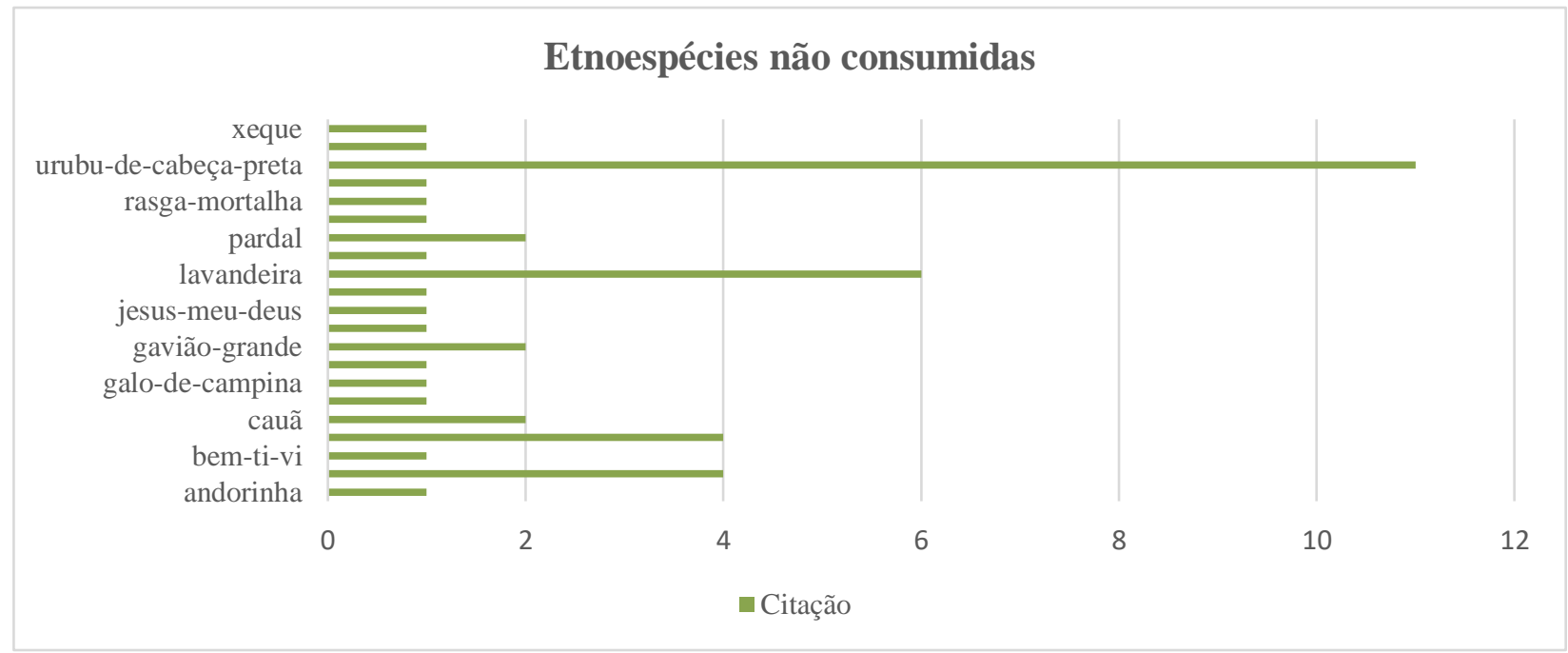

A lavandeira (Fluvicola nengeta) foi considerada pelos entrevistados como uma ave abençoada e protegida por Nossa Senhora ou Jesus Cristo, por isso não é caçada, não servindo como recurso alimentar (Fig 3). Foram retratadas também algumas etnoespécies e a sua abordagem social referente a sua restrição alimentar, além de espécies não consumidas, estando profundamente ligadas a questões religiosas e do próprio comportamento da ave (Fig 4). 
Fig 3. Espécie Lavandeira e Fluvicola nengeta, ave mais citada pelos moradores como não consumida por questões religiosas e espiritualistas.

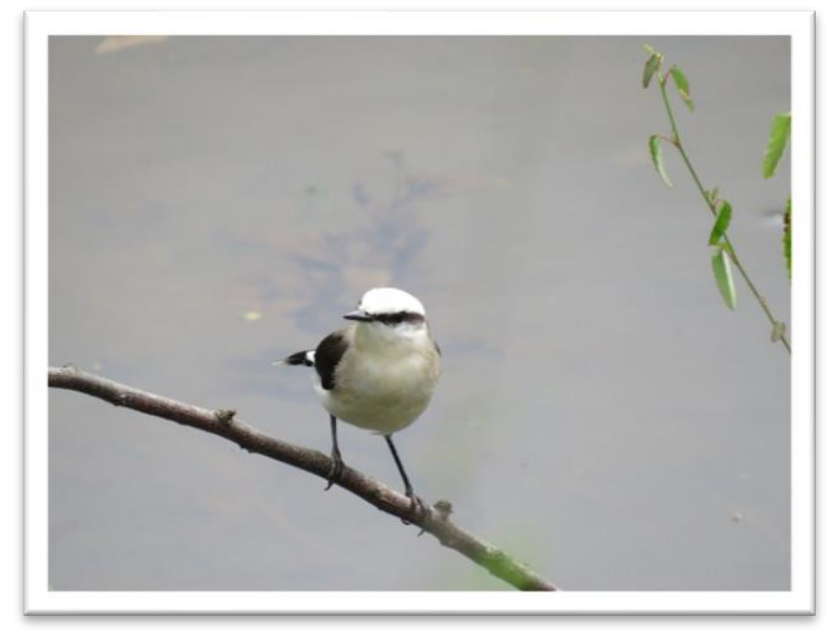

Fig 4. Espécies não consumidas devido o comportamento alimentar. (A) Anum-preto ou Crotophaga ani (B) Carcará ou Caracara plancus (MARQUES, 2020); (C) Urubu-rei ou Sarcoramphus papa; (D) Urubu-de-cabeça-vermelha ou C. atratus.

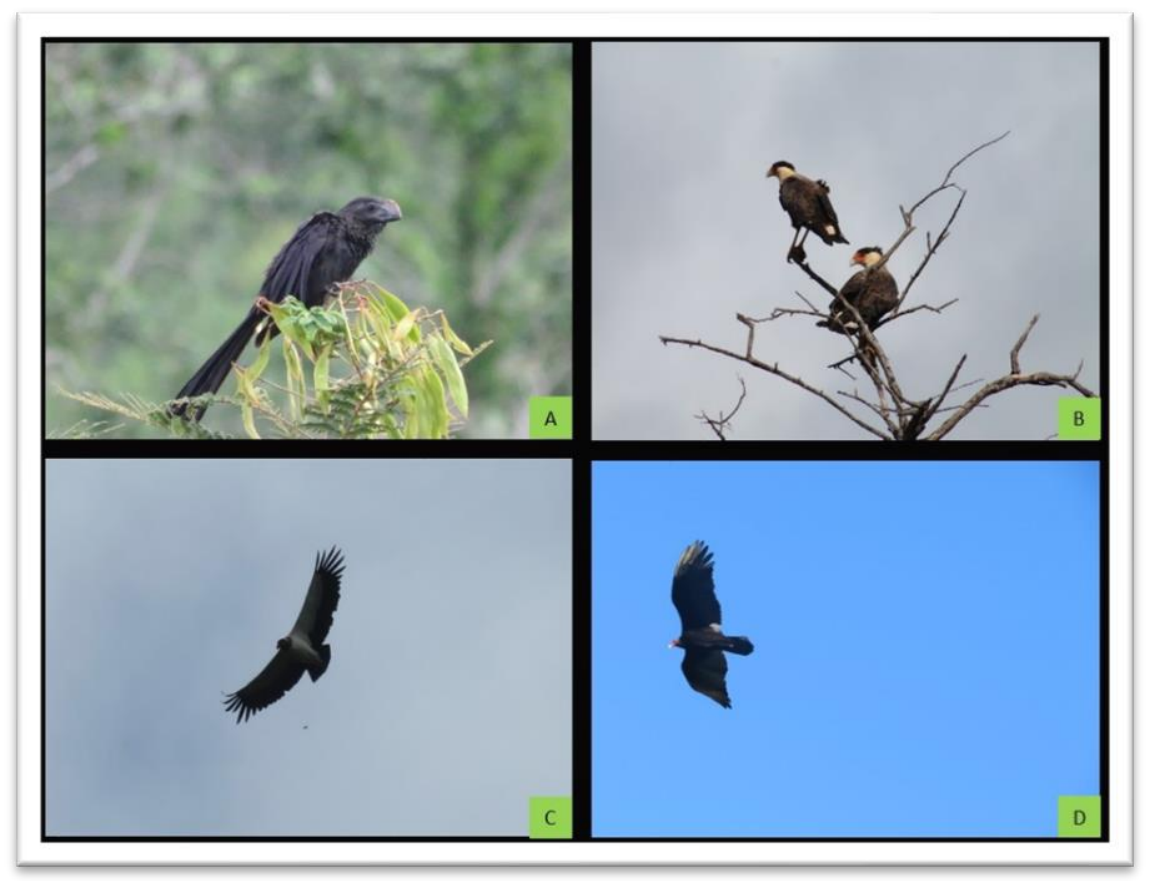


No âmbito do uso zooterápico foram citadas 11 (onze) etnoespécies de aves utilizadas em Catuni da Estrada (Tabela 2). Em relação ao Valor de Uso, a etnoespécies Urubu-de-cabeça-preta (Coragyps atratus) foi a mais citada para o uso medicinal apresentando VU =0,33; Rolinha-caldo-defeijão (Columbina talpacoti) VU = 0,13; Anum-preto (Crotophaga ani) VU = 0,10; A Cauã (Herpetotheres cachinnans), Juriti (Leptotila verreauxi) e a Perdiz (Rhynchotus rufescens) o VU =0,08. Essas aves fornecem 9 (nove) matérias-primas para tratamento de várias enfermidades diagnosticadas localmente (Fig 2). De acordo com os entrevistados as mais utilizadas, são: as penas, fígado, ossos, ave inteira, sangue e piolho.

Tabela 2: Etnoespecies usadas como fonte terapêutica e suas indicações etnomedicinais pelos habitantes do povoado de Catuni da Estrada, Bahia, Brasil, 2020.

\begin{tabular}{|c|c|c|c|}
\hline Etnoespécies & Nome científico & Partes Utilizadas & Indicações \\
\hline Anum-preto & Crotophaga ani & $\begin{array}{l}\text { Penas } \\
\text { Fígado } \\
\text { Bico }\end{array}$ & $\begin{array}{l}\text { Nervos } \\
\text { Doença do vento (derrame) }\end{array}$ \\
\hline Aracuã & Crotophaga ani & Gordura (banha) & Dor de ouvido \\
\hline Cauã & Herpetotheres cachinnans & $\begin{array}{l}\text { Ave inteira } \\
\text { Ossos } \\
\text { Penas }\end{array}$ & Doença do vento (derrame) \\
\hline Coruja & Athene cunicularia & Ave inteira & Alcoolismo \\
\hline Galinha & Gallus gallus domesticus & Penas & Doença do ar \\
\hline Juriti & Leptotila verreauxi & $\begin{array}{l}\text { Sangue } \\
\text { Moela } \\
\text { Ave inteira }\end{array}$ & $\begin{array}{l}\text { Tosse comprida } \\
\text { Catarata }\end{array}$ \\
\hline Pavão & Pavo cristatus & Penas & Doença do vento \\
\hline Perdiz & Rhynchotus rufescens & $\begin{array}{l}\text { Penas } \\
\text { Pé } \\
\text { Moela }\end{array}$ & $\begin{array}{l}\text { Doença do vento } \\
\text { Coluna }\end{array}$ \\
\hline Rolinha-caldo-de-feijão & Columbina talpacoti & $\begin{array}{l}\text { Penas } \\
\text { Ninho }\end{array}$ & Doença do vento (derrame) \\
\hline Rolinha-branca & Columbina picui & $\begin{array}{l}\text { Penas } \\
\text { Ninho }\end{array}$ & Doença do tempo \\
\hline Urubu-de-cabeça-preta & Coragypss atratus & $\begin{array}{l}\text { Penas } \\
\text { Ave inteira } \\
\text { Piolho } \\
\text { Fígado }\end{array}$ & $\begin{array}{l}\text { Tuberculose } \\
\text { Cura de umbigo } \\
\text { Despacho } \\
\text { Asma, etc. }\end{array}$ \\
\hline
\end{tabular}

De acordo com o levantamento, foram citadas 22 (vinte e duas) etnoespécies que são criadas em gaiolas (Anexo IV). Tiveram destaque: Cardeal-do-nordeste (Paroaria dominicana, n=26), Papa- 
capim (Sporophila nigricollis, $\mathrm{n}=15$ ), Coleira (Sporophila caerulescens $\mathrm{n}=15$ ) e Galo-de-campina (Coryphospingus pileatus, $\mathrm{n}=13$ ).

Tabela 3: Etnoespecies criadas em gaiolas e seus respectivos Valores de Uso no povoado de Catuni da Estrada, Bahia, Brazil, 2020.

\begin{tabular}{|c|c|c|c|}
\hline Etnoespécies & Nome científico & Número de Citação & Valor de uso \\
\hline Azulão & Cyanoloxia brissonii & 19 & 0,38 \\
\hline Bigodinho & Sporophila lineola & 6 & 0,12 \\
\hline Canário-da-terra & Sicalis flaveola & 1 & 0,02 \\
\hline Canário-da-serra & Sicalis luteola & 1 & 0,02 \\
\hline Caerdeal & Paroaria dominicana & 26 & 0,52 \\
\hline Coleira & Sporophila caerulescens & 15 & 0,30 \\
\hline Curiatá & Euphonia violácea & 1 & 0,02 \\
\hline Curió & Sporophila angolensis & 1 & 0,02 \\
\hline Trinca-ferro & Saltator similis & 9 & 0,18 \\
\hline Galo-de-campina & Coryphospingus pileatus & 13 & 0,26 \\
\hline Jesus-meu-deus & Zonotrichia capensis & 14 & 0,28 \\
\hline Papa-capim & Sporophila nigricollis & 15 & 0,30 \\
\hline Papagaio & Amazona aestiva & 1 & 0,02 \\
\hline Passo-preto & Gnorimopsar chopi & 9 & 0,18 \\
\hline Pêga & Icterus pyrrhopterus & 1 & 0,02 \\
\hline Priquitinho & Eupsittula cactorum & 1 & 0,02 \\
\hline Pintassilgo & Spinus yarrellii & 1 & 0,02 \\
\hline Rolinha-caldo-de-feijão & Columbina talpacoti & 2 & 0,04 \\
\hline Sabiá-coca & Turdus rufiventris & 7 & 0,14 \\
\hline Sabiá-de-sebo & Mimus saturninus & 6 & 0,12 \\
\hline Sofrês & Icterus jamacaii & 8 & 0,16 \\
\hline Tiziu & Volatinia jacarina & 2 & 0,04 \\
\hline
\end{tabular}

Foi possível observar também uma conexão mágico-religiosa em relação as espécies citadas nas entrevistas. Estas etnoespécies são descritas socialmente como sendo animais que trazem aviso 
de morte ou mau agouro, os que trazem maus presságios, aquelas que prenunciam eventos climatológicos além das aves que anunciam a chegada de visitas.

A maior parte dos entrevistados relataram que as aves da região estão diminuindo e este fator está fortemente ligado ao desmatamento da vegetação local, assim como as queimadas resultantes de crimes ambientais ocorridos na área de serra da comunidade de Catuni. Ainda em relação a implicações conservacionistas, outros fatores também foram citados, como a atividade de caça e a criação de aves de maneira ilegal.

\section{DISCUSSÃO}

Ao observar a identificação e o uso local das etnoespécies, os dados deste estudo dialogam com os resultados encontrados por Galvagne-Loss et al. (2014) em levantamento realizado na comunidade de Pedra Branca, município de Santa Terezinha, Bahia, quando registraram 139 nomes comuns, correspondentes a 117 (84,17\%) espécies acadêmicas.

As etnoespécies mais citadas neste estudo são aquelas que evidentemente provocam alguma influência cultural, pois também são importantes na economia local (Diniz et al., 2012). Cabe destacar que na comunidade de Catuni da Estrada as aves se apresentam como um fator determinante no comércio clandestino e na dieta variante local.

Quanto à preferência de ambientes, os resultados permitem concluir que para estas aves, ambientes montanhosos se constituem um grande refúgio para as diferentes espécies, sendo que delas dependem a sobrevivência dos habitantes da área. As montanhas são percebidas como ilhas ecológicas compostas de diversas espécies endêmicas, graças ao seu isolamento e verticalidade (Netto, Amazile Lopéz; Marques, Juracy, 2020).

A interação trófica de algumas espécies chama atenção para o fato de que algumas delas usadas para esse fim, são classificadas como espécies críticas. Segundo Sick (1997), as famílias Columbidae e Cracidae representam um recurso trófico importante para comunidades humanas em todo o país. Em Catuni, esses animais são bastantes requisitados como uma variação na dieta proteica, sendo citadas como aves que possuem um bom acúmulo de massa corporal e sabor agradável.

Vale citar, no município de Iguatu, Ceará, que um veterinário indicou para consumo humano a carne de Urubu (C. atratus), expondo como funciona a ecologia alimentar do animal e os seus benefícios (rica em proteína, aminoácidos, HDL, etc.). Mesmo com receio, as pessoas começaram a comer e relatos revelaram que a carne era boa e de fácil digestão (Araújo, 1997). Forbes (1881), citou em um artigo que a lavandeira (Fluvicola nengeta), teoricamente teria feito um favor a Virgem Maria e seria um ato de sacrilégio sacrificá-la. 
Para adquirir esses animais e permitir os diferentes usos (interações), foram citados diversos métodos de caça. O conhecimento dessas técnicas é passado de geração em geração e faz parte da cultura no âmbito social em questão.

A caça é uma prática adotada pela humanidade desde a antiguidade, com isso várias técnicas foram e são desenvolvidas para auxiliar na captura e/ou abate das espécies desejadas, sendo adotadas conforme a espécie, o recurso e a finalidade a que se destina o animal capturado (Alves et al., 2010b).

Quando se trata do uso destas espécies em tratamentos zooterápicos, a utilização de partes animais na medicina tradicional, em muitas comunidades, constitui-se de uma importante opção ao tratamento de inúmeras mazelas (Dias et al., 2012).

De acordo com Galvagne-Loss (2013), as matérias-primas derivada das aves mais utilizadas para fins terapêuticos pelos moradores do Povoado de Pedra Branca na Bahia são as penas, os ovos e a banha. Em Catuni também são usadas essas matérias primas para elaboração de remédios.

Neste estudo foi possível observar que, dentre as etnoespécies utilizadas para este fim, a maior parte compreende aves silvestres, sendo identificadas apenas duas etnoespécies domesticas (Gallus gallus domesticus e Pavo cristatus) utilizadas na etnomedicina local.

Assim, as práticas zooterápicas seguem um fluxo místico, sendo chamadas de "curas mágicas" e "simpatias", sendo intrínseco das aves a capacidade de promover a cura de doenças através do rito simbólico de medicar o enfermo sem que ele saiba a maneira como se deu o tratamento; uma tendência natural na medicina tradicional brasileira (Alves et al., 2007; Alves, 2009). Neste cenário é preciso compreender nitidamente quais as espécies são importantes na relação etnomedicinal em cada território do país. Ela se mostra como uma ferramenta de crucial importância para que se conheça a relação cultural existente entre avifauna e as práticas realizadas pela medicina tradicional nas populações existentes (Souto et al., 2011).

A cultura de criar pássaros em gaiolas é bastante acentuada no povoado de Catuni da Estrada, sendo perceptível o quanto essa prática reverbera pelos espaços. Trata-se de questões culturais transmitidas para as gerações do presente.

Estas aves apresentam características marcantes, como o canto, a beleza de suas plumagens, além de estarem altamente ameaçadas a extinção. O interesse da criação em cativeiro (gaiolas) e o comércio ilegal, muitas vezes é mantido por vários tipos de consumidores, resultando no declínio populacional de várias espécies.

A partir da fiscalização do Instituto Brasileiro de Meio Ambiente e dos Recursos Naturais Renováveis (IBAMA) frente ao hábito de criar pássaros em gaiolas, alguns entrevistados dizem haver um aumento de algumas populações, como no caso do Papa-capim e do Coleira.

Citado por Pimentel e Santos (2009), a cultura de criar pássaros canoros e de pequeno porte está concentrada no Estado da Bahia, sendo o Cardeal (Paroaria dominicana) a ave que possuiu o 
maior número de indivíduos apreendidos pela fiscalização preventiva, seguidos de Azulão (Cyanoloxia brissonii), Canário-da-terra (S. flaveola), Pássaro-preto (C. chopi), Estevão (S. similis) e Papa-capim (Sporophila nigricollis). Na comunidade de Catuni da Estrada é comum tais espécies serem criadas como animais de estimação.

Para além do uso como animais de estimação, a identificação do uso de algumas espécies para fins mágico-religiosos pode ser explicada pelo fato de que várias aves também possuem vocalização que "prenunciam" chuva; tal fato acontece, geralmente, por que os fatores climáticos influenciam tanto na época reprodutiva quanto no canto das aves (Magalhães, 1952; Sick, 1997; Kizungu et al., 1998; Araujo et al., 2003).

De acordo com Marques (2002), o canto desses animais são sinais do mundo animal que os seres humanos atribuem sentidos e valores, sendo chamado de transmutação zoosemiótica. Neste conceito, destaca-se o ornitoáugures, constituído por "vocalizações que têm o poder de prenunciar ocorrências naturais e/ou "sobrenaturais", sendo abordado como um fenômeno transcultural.

Várias aves emitem sons melodiosos, que, culturalmente, são entendidos de diferentes perspectivas, fazendo parte dos mitos, superstições e lendas populares, tornando-se componente integrante do folclore (Teschauer, 1925; Nomura, 1996; Sick, 1997). Logo, na comunidade em questão são vários os mitos abordados pelos atores sociais, visto que algumas aves são fortemente vistas como agourentas. Assim, são abatidas numa perspectiva de ser bloqueada a energia que supostamente é emitida pelo canto e performance das aves ao redor das moradias.

A compreensão da cultura local destaca-se como um componente indispensável para o entendimento das relações entre seres humanos e aves, e as implicações que podem gerar em relação à conservação dessas espécies. A fragmentação e perda do habitat, ocasionado pela supressão da vegetação nativa, induz vasta consequência para as populações de aves locais, sendo as espécies sensíveis ou especialistas as mais afetadas (Santos; Costa-Neto, 2007). A percepção dos entrevistados relacionada à conservação da avifauna é visível ao narrar possíveis motivos pelos quais as aves estão em processo de diminuição.

Assim, torna-se urgente a produção de conhecimento da biodiversidade local. A implantação de parques eólicos na região serrana também é responsável por provocar impactos profundos na avifauna local, principalmente para as espécies que necessitam de grandes áreas para levantar voo, bem como os hábitos migratórios (Drewitt e Langston, 2006). Outro fator direto ligado a este impacto é a colisão de aves nas torres eólicas. Estimativas médias de mortalidade anual nos EUA em turbinas eólicas quantificam as colisões variando entre 20.000 e 573.000 pássaros por ano (Erickson et al., 2001, 2005; Manville, 2009; Sovacool, 2012; Smallwood, 2013).

Assim, seria importante perguntar para as comunidades tradicionais quais as áreas prioritárias para conservar a biodiversidade e quais estratégias fariam mais sentido. Vale lembrar que as aves

Revista Ouricuri, Juazeiro, Bahia, v.11, n.1. p.029-050. jan./jul., 2021. http://www.revistas.uneb.br/index.php/ouricuri | ISSN 2317-0131 
constituem um dos grupos mais estudados, no sentido ecológico e taxonômico, sendo animais essenciais como bioindicadores e na identificação de áreas de endemismo e daquelas prioritárias para implantação de projetos conservacionistas (Eken et al., 2004).

Nesta ótica, pode-se citar o potencial das aves para a prática de observação de aves. Comumente chamada de Passarinhar, essa atividade é responsável por promover diversos fatores que auxiliam na promoção do bem estar das populações humanas e das aves. Sendo responsável por movimentar o turismo local, contribui para a conservação e sensibilização das pessoas, além de gerar dados quantitativos para a ciência cidadã. Tais dados, muitas vezes, são usados para entender padrão de distribuição e riqueza de espécies.

O entendimento etnoornitológico da comunidade de Catuni da estrada aqui registrado permite perceber que existe uma relação muito sensível dos moradores com a avifauna local. Tais performances são observadas através de diversas interações que vão desde a relação trófica, passando pelo uso na medicina tradicional, o contato sócio afetivo através do canto e beleza de plumagens, bem como a variante socioeconômica, pois toda ave utilizada como animal de estimação tem potencial econômico através da venda no comércio ilegal.

\section{REFERÊNCIAS}

Albuquerque, U. P; Lucena, R. F. Métodos e técnicas para coleta de dados. In: Métodos e técnicas na pesquisa etnobotânica. Recife: NUPEEA/ Livro Rápido, 2004, p. 37-62.

Alves, R. R. N., Pereira Filho, G. A. Commercialization and use of snakes in North and Northeastern Brazil: implications for conservation and management. New York: Biodiversity Conservation, (16), 969985, 2007.

Alves, R. R. N.; Souto, W. M. S.; Mouro, J. S. A Etnozoologia no Brasil - Importância, status atual evperspectivas. Recife: Nupeea, 347-378, 2010b.

Alves, R. R. N., Mendonça, L. E. T., Confessor, M. V. A., Vieira, W. L. S., Lopez, L. C. S. Hunting strategies used in the semi-arid region of northeastern Brazil. Journal of Ethnobiology and Ethnomedicine, (5),12, 2009.

Alves, R. R. N. Fauna used in popular medicine in Northheast Brazil. Journal of Ethnobiology and Ethnomedicine (5), 1, 2009.

Alves, R. R. N.; Souto, W. M. S. Etnozoologia: conceitos, considerações históricas e importância, 1940, 2010. In: Alves, R.R.N.; Souto, W.M.S.; Mourão, J.S. (Eds). A Etnozoologia no Brasil - Importância, Status atual e Perspectivas. Recife: Nupeea: 550.

Araujo, H. F. P.; Mourão, J. S. 2003. “... QUANDO O ANUM CHORA TÁ AVISANDO CHUVA”: PERCEPÇÃO ETNOECOLÓGICA DE MORADORES DE COMUNIDADES RURAIS NO MUNICÍPIO DE SOLEDADE - PB. In: Congresso Brasileiro de Ornitologia, 19, 2003. Feira de Santana. Resumos 
do XI Congresso Brasileiro de Ornitologia. Feira de Santana: Sociedade Brasileira de Ornitologia, 2003. P.19.

Araujo, S. Carne de urubu chega à mesa do nordestino. Diário de Pernambuco, Recife, 1997. BEGOSSI, A. Ecologia Humana: um enfoque das relações homem-ambiente. Interciência, (18), 121132, 1993.

Bennett, E. L.; Robinson J. G. Hunting for Sustainability: The start of a synthesis. In Hunting for sustainability in Tropical Forests Edited by: Robinson JG, Bennett EL. Biology and Resource Series. Columbia University Press, New York, 499-519, 1999.

Biernacki, P. E.; Waldorf, D. Snowball sampling problems and techniques of chain referral sampling. Sociological Methods and Research, (10), 141-163, 1981.

Brasil. Ministério do Meio Ambiente. Livro Vermelho da Fauna Brasileira Ameaçada de Extinção, 2018, (1), p. 1420.

Comitê Brasileiro De Registros Ornitológicos (2015) Listas das aves do Brasil. 10ª Edição. Disponível em <http://www.cbro.org.br>. Acesso em: 15 de novembro de 2020.

Corona-M, E. Apuntes sobre lãs relaciones hombres-fauna, como un escenario del dialogo de saberes. In: Villamar, A. A; Corona-M, E.; Martinez, P. H. (coord) Saberes colectivos y dialogo de saberes em Mexico, 2011.

Dias, T. S.; Barbosa, T. S.; Corrêa, V. R.; Carvalho, L. S. L.; Baía Júnior, P. C. Animais de uso medicinal: Produtos e subprodutos comercializados no município de Abaetetuba, Pará, Brasil. In: Congresso Brasileiro de Zoologia. Anais do XXIX Congresso Brasileiro de Zoologia. Salvador: Sociedade Brasileira de Zoologia, 2012, (29), p. 1546.

Diniz, W. J. S.; Lima, C. N.; Lyra-Neves, R. M.; Telino Júnior, W. R. Estudo etnoornitológico no Remanescente Quilombola Estivas, Garanhuns, Pernambuco. In: Congresso Brasileiro de Zoologia, 29. Anais do XXIX Congresso Brasileiro de Zoologia. Salvador: Sociedade Brasileira de Zoologia, 2012, p. 276.

Drewitt, A. L.; Langston, R. H. W. Assessing the impacts of wind farms on birds.lbis, 2006, (148), p. 2942.

Eken; G.; Bennun; L.; Brooks; T.M.; Darwall; D.; Fishpool; L.D.C.; Foster; M.; Knox; D.; Langhammer; P.; Matiku; P.; Radford; E.; Salaman; P.; Sechrest; W.; Smith; M.L.; Spector; S.; Tordoff; A. Key Biodiversity Areas as Site Conservation Targets. BioScience, (54), 1110-1118, 2004.

Erickson, W. P., Johnson, G. D., Strickland, M. D., Young Jr., D. P., Sernka, K. J., Good, R. E. 2001. Avian collisions with wind turbines: a summary of existing studies and comparisons to other sources of avian collision mortality in the United States. National Wind Coordinating Committee Resource Document. Disponível em: < https://www.osti.gov/servlets/purl/822418/> Acesso em: 15 de novembro de 2020.

Erickson, W. P.; Johnson, G. D.; Young Jr., D. P. A summary and comparison of bird mortality from anthropogenic causes with an emphasis on collisions. General Technical Report PSW-GTR-191. U.S. Department of Agriculture, Washington, D.C., 2005.

Revista Ouricuri, Juazeiro, Bahia, v.11, n.1. p.029-050. jan./jul., 2021. http://www.revistas.uneb.br/index.php/ouricuri | ISSN 2317-0131 
Farias, G. B. E; Alves, A. G. C. Aspectos históricos e conceituais da Etnoornitologia. Biotemas, (20), 91-100, 2007.

Forbes, W. A. Eleven weeks in north-eastern Brazil. Ibis, 1881, (4), 312-362.

Galvagne-Loss. Etnoornitologia no Povoado de Pedra Branca, município de Santa Terezinha, Bahia. Dissertação (Mestrado em Zoologia) - Universidade Estadual de Feira de Santana. 2013.

Galvagne-Loss. Ethnotaxonomy of birds by the inhabitants of Pedra Branca Village, Santa Teresinha municipality, Bahia state, Brazil. Journal of Ethnobiology and Ethnomedicine, (10), 55, 2014.

HUNTINGTON, H. P. Using Traditional ecological knowledge in science: Methods and applications. Ecological Applicationsm, (10), 1270-1274, 2000.

Kizungu, B., Ntabaza, M. E Mburunge, M. Ethnoornithology of the tembo in eastern drc (former zaire): part one, kalehe zone. African Study Monographs, (19), 103-113, 1998.

Magalhães, J. Previsões Folclóricas das Secas e dos Invernos no Nordeste Brasileiro. Rev. Antropol, (33), 253-368, 1952.

Manville, A. Towers, turbines, power lines, and buildings-steps being taken by the U.S. Fish and Wildlife Service to avoid or minimize take of migratory birds at these structures. Proceedings of the Fourth International Partners in Flight Conference: Tundra to Tropics 262-272, 2009.

Mason, O.T. Aboriginal American zootechny. American Anthropologist, (1), 45-81, 1899.

Mello, L. G. Antropologia cultural. Rio de Janeiro: Editora Vozes, 1995.

Netto, A. L; Marques, J. Ecologia Humana em Ambientes de montanha. Disponível em:<http://salveasserras.org/nosso-banco-de-dados/>. Acesso em: 06 Novembro de 2020.

Nomura, H. Avifauna no folclore. Fundação VingtUm Rosado, Secretaria de Educação, Cultura e Desporto do Rio Grande do Norte, Mossoró, Brasil. 1996.

Phillips, O.; Gentry, A. H.; Reynel, C.; Wilki, P.; Gávez-Durand, C. B. Quantitative ethnobotany and Amazonian conservation. Conservation Biology, (8), 225 - 248, 1994.

Pimentel, P. C. B.; Santos, J. M. Diagnóstico do tráfico de animais silvestres no estado da Bahia: identificação, quantificação e caracterização das espécies-alvo. Diálogos \& Ciência - Revista Da Rede De Ensino FTC. Ano III, 8, 2009.

Posey, D. A. Etnobiologia: teoria e prática. Em: Ribeiro, D. Suma etnológica brasileira. 1. Petrópolis: Vozes. 1987.

Santos, I. B.; Costa-Neto, E. M. Estudo etnoornitológico em uma região do Semi-árido do Estado da Bahia, Brasil. Sitientibus Série Ciências Biologicas, (7), 273-288, 2007.

Sick, H. Ornitologia Brasileira. Edição Revista e Ampliada por José Fernando Pacheco. Rio de Janeiro: Nova Franteira. 1997.

Sigrist, T. Guia de Bolso Avis Brasilis - Avifauna Brasileira. São Paulo: Avis Brasilis, 336, 2015.

Silveira, R. A. Conhecimento Ecológico Tradicional de aves da comunidade Cuiabá Mirim, Pantanal de Mato Grosso: 153 f. (Dissertação) - Universidade do Estado de Mato Grosso. 2010. 
Smallwood, K. S. Comparing bird and bat fatality-rate estimates among North American wind-energy projects. Wildlife soc. B., (37), 19-33, 2013.

Souto, W. M. S.; Vieira, W. L. S.; Montenegro, P. F. G.; Alves, H. N.; Alves, R. R. N. Breve revisão sobre uso de fauna medicinal no Brasil: aspectos históricos, farmacológicos e conservacionistas. Sitientibus série Ciências Biológicas, (11), 201-210, 2011.

Sovacool, B. K. The avian benefits of wind energy: a 2009 update. Renew. Energ., (49), 19-24, 2012.

Teschauer, C. Avifauna e flora nos costumes, superstições e lendas brasileiras e americanas. Edição da Livraria do Globo, Porto Alegre, Brasil. 1025. 